\title{
Study on Cultural Tourism Industry Integration in Lushan Disaster Area
}

\author{
Zhifeng Zhao ${ }^{1,2, a}$ and Zhiwei $\mathrm{Li}^{2, \mathrm{~b}}$ * \\ ${ }^{1}$ Tourism College, Sichuan University, Chengdu, China \\ ${ }^{2}$ Tourism and Service College, Chongqing University of Education, Chongqing, China \\ a464235085 @qq.com, b407209712 @qq.com
}

Keywords: Lushan; Cultural tourism industry; Integration.

\begin{abstract}
Tourism industry is rated as leading industries and cultural tourism industry integration is one of the important ways in the process of Lushan reestablishment. The paper points out necessity of cultural tourism industry integration, structures integration power system from aspects of competition, demand, government, policy, resident, science and technology; It builds integration support systems through market environment, resource, infrastructure and industrial development; It analyses wags of industrial integration from perspectives of market integration, resources integration, technology integration and function integration. At last, the paper put forward measures of cultural tourism industry integration from aspects of government-guiding, system construction and industrial planning.
\end{abstract}

\section{Introduction}

The Lushan earthquake on April 20th,2013 has been caused heavy economy losses to disaster-hit areas. It has been caused the collapse of disaster-hit areas factories, the damage of production facility, the blocking of transportation and the interruption of electricity. All of which have an huge influence on disaster-hit areas pillar industries like dimension stone, architecture, spinning, water and electricity. For the disaster-hit areas, the primary question of reestablishment is to establish industry strategy-positioning. The establishment of forerunner industry and leading industry has play a vital role in restoration and reconstruction of disaster-hit areas economic system. In the Restoration and Reconstruction of Sichuan Lushan Post-earthquake Tourism Subject Plan(hereafter referred to as reconstruction planning ), The tourism industry is identified as forerunner industry of post-earthquake reconstruction and leading industry of disaster-hit areas sustainable development. The experience of cultural tourism industry development tells us that only by the road of cultural tourism integration, can tourism industry become the regional leading industry. Integration is the best path for the development of tourism industry(Zeng,2011).

With the rapid development of digital technology, communication and computer technology, a range of industry that based on technology boundaries are changing from clear to blear(Zhang,2011). With strong integrity and inclusive, the cultural tourism industry overlaps and has strong correlation with many other industries. thus, the cultural tourism industry and other industries are constantly fusion. In recent years, the emergence of industrial tourism, ecological tourism, science and technology tourism, sports tourism, agricultural tourism are all good examples. However, the cultural tourism integration is in its infancy, and it doesn't have closely and deeply relationship with other industries, especially in the western regions, with less awareness, technology and regulation, all of which make the cultural tourism integration face many problems. The disaster reconstruction planning clearly showed that tourism industry is the leading industry in disaster-hit areas. Only by the road of integration, development of grand tour and construction of big industry, can we realize the goal. Therefore, the study of disaster-hit areas cultural tourism integration has great significance to realize the tourism industry as the leading industry in disaster-hit areas reestablishment. 


\section{Literature Review}

Currently, the study of cultural tourism integration mainly concentrate in following aspect: Firstly, the study of cultural tourism integration motivation, many scholars thought that the tourism is a boundary vague industry, and its high relevancy make it easier to permeate and integrate with other industries(Zhang,2009;Huang,2012). Some other scholars thought tourism way and various tourism type are the decisive factor for the tourism industry integration, the information technology only play a role of booster(Zeng,2011). There also exits scholars thought that the internal motivation of industry integration is the high relevancy and maximization benefit of tourism industry. The external dynamic is the market demand thrust, the pressure of competition cooperation, the pressure of technology innovation and the power of deregulation( $\mathrm{Xu}, 2008)$. The dynamic factors of cultural tourism integration is the tourism demand, pursue of enterprises interests, promote of science technology, competition and cooperation of the market and the policy. Secondly, the study of cultural tourism integration types. Lu (2011)has evolved four patterns of tourism industry integration, that is, technical penetration, resource sharing, market development together and function auxiliary. Other scholars like Sun (2011)put forward four patterns of China's tourism development, namely, the integration of coastal tourism and industry, commerce and trade; the integration of central regions and history and culture; the integration of western tourism and natural ecological protection; the integration of border provinces and autonomous regions tourism and border trade. Wang (2007) divided tourism industry integration into three types: correlation integration, functional integration and structural integration. Yang (2008) thought tourism integration can divided into the integration of tourism and other services and also the integration of tourism and other non-services. There also some scholars put forward that the cultural tourism integration can divided into cross integration, penetration integration and recombination integration(Zhang,2011). Thirdly, the process and path of the tourism industry integration. $\mathrm{Li}(2008)$ took the integration of scenic spots industry and animation industry as an example and analysis the specific process of the two's mutual integration. Ma (2010)pointed out that when the enterprises looking for the tourism integration, the first thing is to find out market dynamics of the two industries, then captures the integration point and at last embraces and masters innovation. $\mathrm{Li}$ (2009)proposed three path of tourism industry integration: extensive casualness,abroad servitization, standardization and modularization. Shi (2011) also generalized three path of tourism industry integration. namely, the integration of tourism and primary industry; the integration of tourism and secondary industry; the integration of tourism and tertiary industry. At last, the influence and effect of tourism industry integration. $\mathrm{Li} \mathrm{(2006)} \mathrm{put} \mathrm{forward} \mathrm{that} \mathrm{the} \mathrm{integration} \mathrm{of} \mathrm{business} \mathrm{and} \mathrm{tourism} \mathrm{make}$ the network structure be the foundation of business travel. Xu (2011) put forward that tourism industry integration can show four effects, that is, value compound, innovation of resources, variety of products and promotion of tourism attitude.

In conclusion, the cultural tourism integration has been the hot topic in academic circles and also has been formed a series of research consensus. It has been widely researched on its motivation, pattern, type, process, path and effect. However, the current studies on tourism integration is vague and many of them are copied from other industries integration research results. There isn't much cultural tourism integration study combined with specific cases. And at the same time, there were less attention on cultural tourism integration in the previous study on disaster reconstruction plan. By this, set out from Lushan disaster-hit areas cultural tourism integration, and combined with the theory of systematology, the paper analysis the internal mechanism of disaster-hit areas cultural tourism integration, hoping to enrich theory and practice of cultural tourism integration.

\section{The necessity analysis of disaster areas cultural tourism integration}

The necessity of disaster areas reestablishment. The reconstruction planning paid highly attention on tourism industry and made it as forerunner and leading industries. As a strong correlation 
industry, cultural tourism industry has a cross with other industries. So, actively promote the cultural tourism integration and reference the resources, market and technology of other industries will enlarge its attraction system, innovative its products, enhance its attraction, exploit its market, improve its service facilities. Thus, the development of cultural tourism integration has an important practical significance on realization of the goal, which is established in the reconstruction planning to establish tourism industry as the forerunner and leading industries .

The necessity of disaster areas development strategy. According to the different regions resource environmental bearing-capacity, existing development density and future developmental potential, the main functional regions divided the national land space into different spatial unit. From the perspective of development method, it can divided into priority exploitation, major exploitation, limit exploitation and prohibition exploitation. From the development contents, it can divided into urbanized areas which mainly provide industrial and servicing products, agricultural areas which mainly provide agricultural products and ecological areas which mainly provide ecological products. In the National Main Functional Areas Planning and Sichuan Main Functional Areas Planning, Lushan disaster-hit areas are limit exploitation areas in national level, and the areas like the Giant Pandas' Habitat, Fengtongzhai National Nature Reserve, Jiajinshan National Forest Park are belong to prohibition exploitation.Therefore,Ya'an set the goal of establish the international regional ecological city, and makes sample and example for national and Chengdu-chongqing economic zone ecological cities and uses the ecology to coordinate the development of regions economy. Using the advantages of ecology to develop cultural tourism industry, and by the road of integration, all of which are meet disaster areas development strategy.

The necessity of industrial structure adjustment and upgrade. Lushan earthquake disaster areas have an unsound industrial structure,so it urgent need to adjustment and transition to ensure the sustainable development of its economy,society and ecological environment. The proportion of tertiary industry in disaster-hit areas is lower, so it needs to constantly increase its proportion to promote local economic development. The output value of tertiary industry in disaster areas mainly contributed by low level service industry, which has low added value and doesn't have strong connections with relevant industries. The cultural tourism industry belongs to high level service industry, so it can effectively promote the development of other industries. By the road of cultural tourism integration in disaster areas, it is beneficial to add the output value of tertiary industry and elevate its proportion and the it is also the needed of update the service level.

The necessity of economic development pattern transformation in disaster areas. With the constant development of economy, the people in disaster areas also aware the importance of protect the environment and resources. It isn't desirable to pursuit one-side economic growth at the cost of environment or resources. Therefore, the disaster areas set the goal of establish the international regional ecological city, and use the ecology to coordinate the development of local economy. Thus, it needs to reduce the proportion of high energy consumption and high pollution industries and promote the proportion $\mathrm{f}$ tertiary industry. The development of cultural tourism integration is one of the methods to transform the economic development pattern.

\section{The analysis of cultural tourism integration pattern and solution in disaster areas}

The systematology analysis of cultural tourism integration. The analysis of fusion power system.

Various power promoted cultural tourism integration, and made up the fusion power system. The government, enterprises, demand and technology play an important role in it. For Lushan earthquake disaster areas, the government should play a leading role in promoting the cultural tourism integration. The disaster reconstruction planning clearly established the tourism industry as the forerunner and leading industries in disaster-hit areas. In order to achieve the goal as soon as possible,the government 
must promote the cultural tourism integration and set up the development philosophy of tourism insight and build big industry. To promote it from city planning, funds and policy. In order to better meet the demands of tourists, the cultural tourism enterprises in disaster areas must add the diversity, experience and intellectual elements. Thus it needs to take the path of constantly integration with other industries. The demand factor plays an important role in promoting industry integration. the diversification consumption demand and individuation directly led the non-boundary of tourism attractions and the elements of other industries alienated into tourism attractions. Some research results pointed out that the cultural tourism integration only play a subsidiarity role. The author thinks that the competition of tourism industry is the competition of science and technology and talents in nowadays than the competition of resources. More and more resources detachment products, for example the Disneyland and animation tourism, are completed by science and technology and talents. In promoting the cultural tourism integration, the technology cannot be ignored. The vacation resources in disaster areas have a high level, but there's a fly in the ointment:there are lower and less tourist attractions. The development of vacation tourism cannot continue without tourist attractions. The disaster areas can develop resources detachment products by the means of science and technology. Combined the culture with science and technology to promote the local cultural tourism integration.

The citizens, enterprises competition and policy play an active role in promoting the cultural tourism industry integration. In the process of reconstruction, the affected residents took an active part in the construction of cultural tourism industry, which would be conductive to the cultural tourism integration. The cultural tourism integration is also the result of enterprises competition and their mutual development, the enterprises competition prompted them deeply interpenetrated and fused with one another. As the forerunner and leading industries of disaster areas reconstruction planing, the cultural tourism industry needs a series of policies to support. With the mutual effect of government administration department, tourism demand,science and technology, citizens, enterprises competition and policy, and they formed the power system of cultural tourism industry integration.

The analysis of support system

The cultural tourism integration in disaster areas also needs a series of support elements. The infrastructure, market environment, resource base, industrial development, will all affect the degree of disaster areas cultural tourism integration. The disaster areas should take advantage of reconstruction to build stereo type tourist communications network system, and brings the reconstruction areas into Chengdu big economic circle, and also elevate the tourism's accesibility and tourists' distribution function. The disaster areas should invest more in infrastructure so that to create platform for industries integration. In recent years, the domestic tourism market in disaster areas is growing faster, the market demand is constantly increasing, so it urge the enterprises to seek innovation development and cultural tourism integration. The disaster areas faces a favorable market environment, however it doesn't turn the potential market advantage into practical advantage. The disaster areas will put more efforts to recover and revitalize tourism market so that to lay foundation for cultural tourism integration.

The disaster areas should change the traditional cultural tourism resources view and exploit the tourism elements of other industries actively. To realize the cultural tourism function, other industries should integrate into industries integration by the form of cultural tourism resources. The cultural tourism in disaster areas have rich resources, among them, the ecological tourism resources are outstanding. The tourism elements in agriculture, manufacture and service are also abundant, all of these provide a solid foundation for cultural tourism integration. The output value of primary and secondary industries are higher, thus the production value of tertiary industry is lower, the cultural tourism industry need to integrate with other industries to improve the output value of tertiary industry. After the environmental renovation of abandoned industrial mining areas, the disaster areas will explore industrial tourism. After the overall planning and design of old workshops, the city central area are transformed into cultural tourism zone. Add cultural tourism sightseeing leisure programs in agricultural parks around the city. Also, vigorously promote the integrational development of cultural 
tourism and modern service industry. Promote the integration development of cultural tourism and information, finance and logistics. Promote the innovative development of infrastructure such as the tourism transportation and tourism information.

The analysis of integration path

(1)Market Integration

The market integration refers to the cultural tourism enterprises or other industries enterprises develop programs in opponent market field, and it becomes the effective path for the related industries integrated into cultural tourism industry. The tourist real estate, MICE and business travel are typical cases of market integration. By the road of cultural tourism integration, the disaster areas develop these tourism operational types actively. For example, the tourist real estate's development mainly rely on local favorable climate, environment and ecological resources. Lushan has excellent climate and abundant ecological resource, and it also close to major cities like Chongqing and Chengdu, so it is suitable for tourist real estate development.

(2)Resources Integration

Borrowed other industries resources, the resources integration means to develop and utilize these resources to make it be the attractive cultural tourism resources. To develop agricultural tourism, Lushan disaster areas can actively merge cultural tourism industry and agriculture together, and makes full use of its admirable ecological environment, colorful regional culture and geomorphic feature, and also the rustic pastoral scenery, Thus,it can develop agriculture tourism products like leisure agriculture, ecological agriculture, sightseeing agriculture and characteristic tea garden. Meanwhile actively prompts the integration of resources advantage industries and tourism to develop cultural tourism resources from the aspects of products production, labor scene, factory landscape and industrial history.

(3)Technology Integration

The technology integration refers to permeate the value chain activities of other industries partly or totally into another industry by the means of technology, then by mutual blending to form the new industry. The technological means is one of the important means for cultural tourism industry extension. In order to form new tourism formats, the cultural tourism actively introduce new technology like the combination of cultural tourism and animation technology, culture creativity and information technology. Lushan has rich vacation tourism resources with low level. Therefore,by the means of technology, Lushan can create a batch of resources detachment cultural tourism products, which can inject fresh energy to disaster areas tourism.

(4)Function Integration

The cultural tourism has similar social function and role to other industries, so the function integration means affiliate the cultural tourism function into other industries activities. The sports tourism, education tourism, creative tourism and medical tourism are all the models of function integration. With excellent mountain landscape, Lushan disaster-hit areas are suitable for the development of sports tourism like mountain tourism, adventure tourism and outdoor tourism. Lushan is a profound historical and cultural areas, it reserves world cultural heritage of tea culture and ancient tea and horse road and southern silk road, it also has abundant wild fauna and flora, all of these are the ideal place of education tourism and creative tourism.

The study of strategies of cultural tourism integration in disaster-hit areas. .Make plans for disaster areas cultural tourism industry and found a system platform for the development of cultural tourism integration.

Thoroughly arranging disaster areas cultural tourism resources and related industrial factors to find out entry point of industry integration, and work out overall planning of development of cultural tourism industry integration and project planning of industry integration, and also perfect guidance system of industrial planning. The cultural tourism industry and related industries formed new industry pattern, new commercial model and operating ways, all of these need to formulate comprehensive and 
detailed laws and regulations. The government should build organizations that adapted to industry integration, avoid and eliminate the industry barrier formed by overlapping operations by different departments, and coordinate the integration development of tourism industry and related industries. The government, meanwhile, needs to offer incentives for integration of cultural tourism industry and related industries. A series of relevant standards about product development, extension and operation after industries integration should be made, which can direct and promote the standard development of tourism industry integration orderly.

Government-led,increase investment on cultural tourism.

In the process of reconstruction, the government should play a leading role, which is also requirements of the comprehensive and complexity of the cultural tourism integration. The government should actively promote cultural tourism integration and make various policies and straighten its management system. The cultural tourism industry is established as the forerunner and leading industries ,but its foundation is still extremely weak. The reconstruction is in infancy, thus it needs the government to invest more on important tour productions, service facilities of cultural tourism and leisure, infrastructure of cultural tourism.

Lead the participation of enterprises, make incentive policy

To make the reasonable circulation of production factors and different industries are related, the enterprises are encouraged to conduct cross-border business, mergers and acquisitions. Make sure that the role of large tourism conglomerate bring into full play, and encourage it to involved into other related industries and give supports from industrial policy, fiscal and taxation policies and also the monetary policy.

Introduce new technology, promote tourism industry amalgamation.

Technology is the important impetus for tourism industry integration. Therefore, the enterprises needs to actively bring in all kinds of new technologies to enrich the tourism products types and increase the sales channels. At the same time, the government needs to build technology platform for tourism industry integration and provide guarantees for tourism industry to introduce all kinds of technologies.

\section{References}

[1]Zeng Yifu,Yufeng,Big Integration is the Best Path for the Development of Tourism Industry [J].Jiangxi Social Science,2011 (1) : 94-97.

[2]Zhang Hui,Huang Xueying.Basic Thesis of Tourism Industry Integration[J].Tourism Tribune,2011 (4) : 5-6.

[3]Zhang Borui.The development of industries integration and Beijing tourism[J].Urban Problems,2009 (9) : 69-77.

[4]Huang Xijia,Zhouqing.The Coordination Development Strategy of Tourism that is Based on Industrial Integration and Cultural Industries[J],Enterprises Economy,2012（9）: 131-133.

[5]Xu Hong,Fang Qing. The study on the Barriers Factors of China's tourism industry integration and promoting Strategies of its Competition [J] .Tourism Science,2008,22 (4) :1-5.

[6]Lu Bei.The Study of China's Tourism Industry Integration [D] .the Master's thesis of Zhengjiang university,2011, 30-31.

[7]Sun Gennian,Wang Jiejie.The Industries Integration Needs to Act According to Local Circumstances, Tourism Tribune,2011 (5): 8. 
[8]Wang Huimin.The New Development View of Tourism Industry:5C Patterns[J].Chinese Industrial Economy,2007 (6) : 13-20.

[9]Yang Ying.Industries Integration:the New Angle of View of Tourism Development Tendency[J].Tourism Science,2008（4）: 6-10.

[10]Zhang Lingyun.The Base and Presupposition of Tourism Industry Integration[J].Tourism Tribune,2011, 26 (4): 6-7.

[11]Li Meiyun.The Integration and Interaction Development of Tourism Attractions Industry and Animation[J].Tourism Tribune,2008 (1) : 56-62.

[12]Ma Xuefeng,Zhang Shibing,Long Maoxing.The Analysis of Paths of Tourism Industry Integration[J].Economic Geography,2010，30(4) : 678-681.

[13]Li Taiguang,Zhang Wenjiang.Several Reflections about to Promote the Transformation and Upgrading of Shanghai's Tourism Industry[J].The Journal of Beijing International Studies University,2009 (3) : 44-49.

[14]Shi Peihua.The Development Paths and Key Points of Integration of Tourism and Other Industries[J].Tourism Tribune,2011, 26 (5) : 9-10.

[15]Li Pingsheng.Organization Innovation of Business Travel[J].The Journal of Beijing Technology and Business University, 2006, 21 (2) : 100-104.

[16]Xu Wenxiong.The Four Patterns of Tourism Development and Industries Integration[J].Tourism Tribune,2011, 26 (4): 11-12. 